\title{
Clavicle, A Tool For Sex Determination -A Study In South India
}

\author{
Dr. Manjula Thulasi.S ${ }^{1}$, Dr. C.R. Vrijakumari ${ }^{2}$, Dr. Kumar.K.V ${ }^{3}$, \\ Dr. Indira M. $\mathrm{V}^{4}$ \\ (Department Of Anatomy, Dr.S.M.C.S.I Medical College, Karakonam, Trivandrum, \\ University Of Health Sciences, Kerala, India).
}

\begin{abstract}
The clavicle of human body is a long bone placed horizontally. It has two ends, sternal and acromial and a shaft which is curved with a forward convexity in its medial two third and a forward concavity in its lateral one third. It is one of the bones which is used for sex determination especially in cases were only skeletal remains are available for forensic identification. The aim of the study was to assess sex of an individual with the help of various parameters of clavicle in a population in South India The midpoints of sternal (medial) and acromial (lateral) ends were marked and the maximum distance between the two ends of the clavicle was measured with the help of a digital Vernier Caliper (in mm). The mid-shaft circumference was also measured in each clavicle in such a way that the midpoint of the clavicle was marked and its diameter was assessed with the help of a silk thread and measured with the help of a scale. The same researcher did the measurement to avoid individual variation. Presence of rhomboid fossa is also recorded by observing depression near the inferior surface of the sternal end of clavicle.In the present study there is significant differences in length and mid-shaft circumference between male and female clavicle of both sides, the values are higher in males than that of females. The ' $p$ ' value is found to be highly significant in determination of sex by taking these parameters. The present study also compared these parameters with the presence of rhomboid fossa and identified that rhomboid fossa is well-marked and present in males.
\end{abstract}

Keywords: clavicle, parameters, rhomboid fossa, sex determination

\section{Introduction}

Skeleton plays an important role in various sciences like medicine, forensic sciences and anthropology. The clavicle of human body is a long bone placed horizontally. It has two ends, sternal and acromial and a shaft which is curved with a forward convexity in its medial two third and a forward concavity in its lateral one third. It is one of the bones which is used for sex determination especially in cases were only skeletal remains are available for identification. Female clavicle is shorter thinner and less curved and smoother than that of males. Mid shaft circumference is one of the most reliable indicator of sex. The costo- clavicular ligament (ligament connecting the first costal cartilage and inferior surface of sternal end of clavicle) on its attachment in clavicle can produce an impression or depression or marking called rhomboid fossa, which is present in male clavicle especially in younger individuals is another feature used for sex differentiation. The aim of the study was to assess sex of an individual with the help of various parameters of clavicle in a population of South India.

Estimation of sex and age and stature by skeleton is discovered by Krogman and Iscan[1]. Physical anthropologists and forensic pathologists have given utmost importance to the methods of stature estimation from long bones. The advantage of measurement of long bones is that male bones longer and the muscular attachments are more prominent than that of female bones. Skull and pelvis are widely used for sex identification (Standring Susan[2]).The determination of sex by using whole skeleton or bony remnants had been explored by many workers since more than a century and individual bones including clavicle, may help at least in part if not whole. Mid shaft circumference is one of the most reliable indicator of sex and a combination of this measurement with weight and length yields better results (Jit \& Singh [3]). Measurements of clavicle in Western countries have been studied by several researchers (Olivier [4]). For determination of sex of clavicle, various parameters including length, weight, midshaft circumference, cortical index and volume have been studied by various workers (Jit \&Sahni [5]). Several researchers have studied the parameters of the clavicle in different zones of India, Sigh and Gangrade[6]havestudied the measurements of clavicle in Gujarat Zone. Terry et.al, [7]also observed the difference in different parameters of clavicle between Whites and Negros. Hague et $a l$,[8] studied the curvatures of clavicle with its clinical importance. Many studies have conducted the significance of rhomboid fossa in determining the sex of the clavicle and proved that the presence of rhomboid fossa isdeeper and more marked in males. 
Objectives of the study are

\section{Aims \& Objectives of the study}

1. To study morphological features like Length, Mid-shaft circumference and presence of rhomboid fossa in adult clavicle to know the gender difference.

2. To determine sex from unknown skeletal remains of clavicle.

\section{Materials \& Methods}

In the present study 120 clavicles of known sex were collected from the Department of Anatomy of Dr.S.M.C.S.I Medical College, Karakonam, Trivandrum during the period 2009 - 2016. The clavicles were cleaned and dried before the starting of study. Out of 120 clavicles 60 were belonging to right side and 60 were of left side. In those 30 eachwereof males and females of both sides. The length and mid- shaft circumference of each clavicle was studied. For measuring the length, the clavicle was kept on a table, in such a position that anterior and posterior borders were in the same horizontal plane, the midpoints of sternal and acromial ends were marked and the maximum distance between the two ends of the clavicle was measured with the help of a digital Vernier Caliper (in $\mathrm{mm}$ ). The mid-shaft circumference was also measured in each clavicle in such a way that the midpoint of the clavicle was marked and its diameter was assessed with the help of a silk thread and measured with the help of a scale. The presence or absence of rhomboid fossa was also observed and recorded. All the readings were taken twice by same researcher to avoid individualerrors. Samples with defects were excluded. The data collected were analyzed and subjected to statistical analysis using SPSS software. This research study was approved by the Institutional Ethical Board.

\section{Results}

In the present research study a total of 120 adult clavicle of both sex were studied. The most reliable parameters like length and mid shaft circumference of clavicle were measured and statistically analyzed and represented in tables given below. The presence of rhomboid fossa was also noticed in this. In each parameter mean, standard deviation, range, demarcating point of each side were calculated and compared among both sexes.

Table:-1 Statistical Analysis of the length of the clavicle in m.m

\begin{tabular}{|l|l|l|l|l|l|}
\hline \multirow{2}{*}{ Sl.No } & \multirow{2}{*}{ Details Of Measurements } & \multicolumn{2}{|c|}{ Right } & \multicolumn{2}{c|}{ Left } \\
\cline { 3 - 6 } & & Male & Female & Male & Female \\
\hline 1 & Number Of Bones & 30 & 30 & 30 & 30 \\
\hline 2 & Range & $120.40-154.35$ & $112.13-128.27$ & $127.60-154.25$ & $112.13-129.14$ \\
\hline 3 & Mean & 134.57 & 120.53 & 138.44 & 121.78 \\
\hline 4 & Sd & 10.26 & 3.67 & 7.58 & 4.61 \\
\hline 5 & Mean \pm 3 sd & $102.79-166.35$ & $109.42-131.54$ & $115.7-161.18$ & $107.95-134.61$ \\
\hline 6 & Demarcating Point (Dp) & $>131.54$ & & \multicolumn{2}{c|}{10.27} \\
\hline 7 & 'T' Value & \multicolumn{2}{|c|}{7.05} & 102.79 & $>134.61$ \\
\hline
\end{tabular}

Table:-2 Statistical Analysis of the mid- shaft circumference of the clavicle in m.m

\begin{tabular}{|l|l|l|l|l|l|}
\hline Sl.No & \multirow{2}{*}{ Details Of Measurements } & \multicolumn{2}{|c|}{ Right } & \multicolumn{2}{c|}{ Left } \\
\cline { 3 - 6 } & & Male & Female & Male & Female \\
\hline 1 & Number Of Bones & 30 & 30 & 30 & 30 \\
\hline 2 & Range & $29.20-41.20$ & $22.10-32.10$ & $24.15-41.92$ & $22.10-35.30$ \\
\hline 3 & Mean & 35.50 & 26.82 & 34.36 & 27.0 \\
\hline 4 & Sd & 3.37 & 2.40 & 4.08 & 3.02 \\
\hline 5 & Mean \pm 3 sd & $34.02-45.61$ & $19.62-34.02$ & $22.12-46.6$ & $17.4-36.06$ \\
\hline 6 & Demarcating Point $(\mathrm{Dp})$ & $>34.02$ & $<25.39$ & $>36.06$ & $<22.12$ \\
\hline 7 & 'T' Value & \multicolumn{2}{|l|}{11.48} & 7.92 & \\
\hline
\end{tabular}

Table:- 3 Observation of Rhomboid Fossa

\begin{tabular}{|l|l|l|l|}
\hline $\begin{array}{l}\text { Number } \\
\text { clavicles }\end{array}$ & Side & \% of expression of fossa & Female \\
\cline { 3 - 4 } & & Male & 16.6 \\
\hline 60 & Right & 93.3 & 20 \\
\hline 60 & Left & 86.6 & \multicolumn{2}{|l}{} \\
\hline
\end{tabular}




\subsection{Length of the Clavicle 4.1.1Right}

In the present study the length of the male right claviclevaried from120.40-154.35mmwith a mean of 134.57 and that female varied from $112.13-128.27 \mathrm{~mm}$ with a mean of 120.53 .

It was found that the length of the right male clavicle was greater than right female clavicle with a mean difference at $12.9 \mathrm{~mm}$.In the present study no female right clavicle exceeds $134.57 \mathrm{~mm}$ and $59 \%$ of male right clavicle having a length more than $134.57 \mathrm{~mm}$. The smallest right male clavicle is having a length of $120.40 \mathrm{~mm}$ and the right clavicle having a length less than $120.40 \mathrm{~mm}$ is considered as female clavicle. The right clavicle greater than 154.35 is considered as male. The range (mean $\pm 3 \mathrm{SD}$ ) was found to be102.79 -166.35 in males and $109.42-131.54$ in females. The percentage of clavicle beyond Demarkating Points was $33.3 \%$ in males and $0 \%$ in females.

The' $p$ 'value is found to be significant and the ' $t$ ' value was 7.05

\subsubsection{Left}

Length left male clavicle varied from $127.60-154.25 \mathrm{~mm}$ with a mean of $138.44 \mathrm{~mm}$ with an SD 7.58 and the length of left female clavicle varies from $112.13-129.14 \mathrm{~mm}$ with a mean of 121.78 with an SD 4.61

In this study $87 \%$ of the male clavicle was longer than the smallest female clavicle and $42.8 \%$ of the male clavicle is longer than the longest female clavicle and no female clavicle is found to be shorter than the shortest length of male clavicle. Range of the male clavicle was found to be115.7 - 161.18 and that of female was 107.95 - 134.61. It was found that percentage of clavicle beyond D.P was $30 \%$ male and $6.66 \%$ female. The' $t$ 'value was 10.27. These measurements are represented in TABLE- 1

\subsection{Mid-shaft Circumference 4.2.1 Right}

The mid - shaft circumference of the right clavicle varied from 29.20-41.20 mm and that of female rages from 22.10-32.10.The mean circumference of male was found to be 35.50 and SD was 3.37 and that of female was noticed as 26.82 and 2.40 respectively. The range (mean $\pm 3 \mathrm{SD}$ ) was noticed between $25.39-45.61$ in males and $19.62-34.02$ in females. The percentage of clavicle beyond Demarcating point was $26.6 \%$ males and $20 \%$ females.

The ' $p$ 'value is found to be significant and ' $t$ ' value was noticed as 11.48 .

\subsubsection{Left}

The mid shaft circumference of the left male clavicles varied from $24.15-41.92 \mathrm{~mm}$ and that of left female clavicle ranges from $22.10-35.30 \mathrm{~mm}$. The mean and the SD of male 34.36 and 4.08 and of female is 27.0 and 3.02 respectively. The range was noticed between $22.12-46.6$ in males and $17.98-36.06$ in females.

Out of the male clavicles $78.5 \%$ had the circumference greater than the highest figure for female mid shaft circumference and 33.3\% had female clavicles had the circumference lesser than the lowest figure for male mid - clavicular circumference. The DP was 36.06 for males and 22.12 for female. Of male clavicles $36.6 \%$ was beyond the Demarkating point but in females no one $(0 \%)$ was beyond DP.The 't'value was noticed as 7.92. Represented in TABLE-2

\subsection{Rhomboid Fossa}

The rhomboid fossa is present at the inferior surface of sternal end of the clavicle which is seen as a prominent depression in male clavicles. Of the male clavicles studied $93.3 \%$ of right side and $86.6 \%$ left side clavicles showed a depressed area near the sternal end.But in females only $16.6 \%$ right and $20 \%$.left sideclavicle showed the same. These observations were represented inTABLE-3. The rhomboid fossa that was observed in females showed less depressed area than that of males.

\section{Discussion}

The difference in measurements can be occurred due to racial genetic and environmental factors. The determination of the sex and age of a dead human being or the skeletal remains is very important and crucial. It is not a difficult task when a complete skeleton is available, but the accuracy of assessment of the sex of the skeleton is directly proportional to the number of bones available (Krogman1973[9]). For determination of sex of clavicle, various parameters including length, midclavicular circumference, cortical index and volume have been studied by various workers (Jit \& Sahni [5]). Establishing the identification criteria for clavicle male bones is longer, thicker and heavier than that of female bones. In the present study length and mid-shaft circumference were measured and compared in both sides and both sexes and significant difference were found out.

In the present study the length of the right male clavicle varied from $120.40-154.35 \mathrm{~mm}$ and left male clavicle varied from $127.60-154.25 \mathrm{~mm}$ with a mean difference of 134.57 and 138.44 . The length of the right 
female claviclevaried from 112.13-128.2mm and that of left female clavicle between 112.13 and $129.14 \mathrm{~mm}$ with a means of 120.53 and 121.78 respectively. The left male clavicle showed marked difference in length, that is $3.87 \mathrm{~mm}$ more than of right clavicle,but in females the difference was less markable that is $1.25 \mathrm{~mm}$ more on left side. Jit et.,al[3], a study in Amritsar zone has also proved the similar results. Butanother studyconductedbySingh et., al[6]in Varanasi zone the length of right clavicle was longer than that of left. A study conducted by Oliver [4], in different races also compared the length of the clavicle and proved that the length of left clavicle is longer than that of right.

Generally female clavicle is shorter, thinner, less curved and muscular impressions are less marked than males. These external assessments may not be correct and shows subject variations, but it should be correlated with different parameters to get scientific validity.Jit and Sahni [5]found out that material sexing of clavicle by lengthmeasurements will give good results. The present analysis also stressed the difference in length between both sexes. The lengths offemale clavicles of both sides were lesser than that of males. Themean difference of right and left male clavicle was 134.57 and 138.44 and that of female was 120.53 and 121.78 respectively. This results in the present research study also proved that the majority of male clavicles of both sides are longer than the female clavicles. The mean length of right clavicle of male is14.04 greater than that of female and on consideration of clavicle of left side the difference was 16.66 which was found to be very significant in this study.

In the present study the mid shaft circumference of the rightmale clavicle ranged from $29.20-41.20 \mathrm{~mm}$ and that of female of the same sideshowed 22.10-32.10mmand on the left side the circumference was24.15 $41.92 \mathrm{~mm}$ and $22.10-35.30$ in males and females respectively. This study also shows that the range was higher in right sided clavicle. Themean circumference was 35.50 (male) and 26.82(female) in right side and 34.36 (male) and 27.0 (female) in left side. Female clavicles of right side were $8.68 \mathrm{~mm}$ shorter than male clavicle and that of left side were $7.36 \mathrm{~mm}$ shorter. Many previous studies also showed similar results. The study conducted by Terry [7] in American Negro population and Jit and Singh [3] in Indian population showed similar results. This research study is also under the conclusion that mid shaft circumference was also one of the reliable criterions for the determination of sex.

Many studies have conducted to determine the sex of the clavicle with the help of rhomboid fossa. Studies conducted by Jit and Kaur [10], Singh \& Singh [11] in North Indian population considered rhomboid fossa as a reliable indicator of age and sex. Rhomboid fossa is more marked (90\%)in male clavicles. Approximately $10 \%$ of female clavicle represented this as a small smooth area (it is not found as a depression in that of male clavicle). The study conducted by Shobha [12], the rhomboid fossa along with other parameters is highly significant predictors of sex. The present study also compared the morphological features with the presence of rhomboid fossa and came to the conclusion that majority of the male clavicles studied showed rhomboid fossa (93.3\% of right side and $86.6 \%$ left side) and the incidence is minimal in females.

\section{Conclusion}

To determine the sex of clavicle, 120dried bones of known sex which were in good condition were collected from the department of Anatomy of Dr, S.M.C.S.I Medical College, Karakonam. Different morphological features (parameters) were measured and studied and the presence of rhomboid fossa was also observed and recorded. The measurements were statistically analyzed and compared with the values available.The present analysis there is negligible difference in length and mid-shaft circumference between male clavicles of right and left sides. But there is significant difference in these parameters between male and female clavicle of both sides, the values are higher in males than that of females. By this method, taking length as the parameter the sexing of $66.7 \%$ of male and $100 \%$ of female clavicle of right side and $70 \%$ of male and $93.3 \%$ of female clavicle of left sidecould be determined. Similarly taking the mid-shaft circumference alone the sexing of $73.4 \%$ of male and $80 \%$ of female clavicle of right side and $63.4 \%$ of male and $100 \%$ of female clavicle of left side could be predicted. The incidence washigher by observing the rhomboid fossa ie, $93.3 \%$ of male right sided clavicle and $86.6 \%$ on the left sided clavicle showed the fossa as a prominent depression. This study also proves that for determining the sex of the clavicle the most reliable method is thecombination of length, mid- shaft circumference with rhomboid fossa.

\section{References}

[1]. Krogman,W.M and Iscan, M.Y Human skeleton in Forensic Medicine $2^{\text {nd }}$ Edition, Charles.C.Thomas, Spring field, 1986

[2]. Standring Susan, Gray's anatomy the anatomical basis of clinical practice $40^{\text {th }}$ edi, Churchill Livingstone, Elsevier, 2008, p, 791-792

[3]. Jit I, Singh S. The sexing of adult clavicles, Indian journal of medical research 1966; 54-551-571

[4]. Olivier.G (1951) Anthroplogie de la clavicule. Bulletin etmemoried de la societe D' Anthropologie Paris 2 10e serie 121-157

[5]. Jit I, Sahni D 1983. Sexing the North Indian clavicles.Journal of Anatomical Society of India, 32(2): 61-72

[6]. Singh.S Gangrade KC (1968) The sexing of adult clavicles demarking points for Varanasi zone. Journal of the Anatomical Society of India17: 89-100

[7]. Terry RJ (1932) The clavicle of the American Negro Physical Anthropology.

[8]. Hague MK et al, Study of curvatures of clavicle with its clinical importance, Kathmandu univ Med J.2011; 3694) 279-282 
[9]. Krogman WM 1973. The Human Skeleton in forensic Medicine:Sexing of Skeletal Remains. Springfield:Charles C Thomas Publishers, $141-153$.

[10]. Jit I, Kaur H. Rhomboid fossa in the clavicles of North Indians. Am J Phys Anthropol.1986; 70:97-103.

[11]. Shobha. Determination of sex of adult human clavicle bymorphometric parameters. [dissertation]. Bangalore, Karnataka, India. Rajiv Gandhi University of Health Sciences. 2010.

[12]. Singh M, Singh D (2009) Rhomboid Fossa of Clavicle: Is It A ReliableEstimator of Gender and Age of Northwest Indian Subjects of Chandigarh Zone. Journal of Punjab Academy of Forensic Medicineand Toxicology, 9(1): 58-65. 